\title{
Produtividade e qualidade do milho doce em diferentes populações de plantas
}

\section{Yield and quality of sweet corn at different plant populations}

\author{
Renan Soares de Souza ${ }^{1 *}$; Pedro Soares Vidigal Filho²; Carlos Alberto Scapim²; \\ Odair José Marques²; Dyane Coelho Queiroz ${ }^{3}$; Ricardo Shigueru Okumura ${ }^{4}$; \\ Deivid Lincoln Reche ${ }^{5}$; Vinícius Bovo Cortinove ${ }^{6}$
}

\begin{abstract}
Resumo
O objetivo do presente estudo foi avaliar o efeito da população de plantas sobre os componentes de produção e a composição química de grãos de dois híbridos de milho doce no cultivo de "Inverno Primavera". O delineamento experimental utilizado foi o de blocos completos casualizados com quatro repetições. Os tratamentos constituíram-se da combinação entre híbridos de milho doce (Tropical Plus e RB-6324) e populações de plantas $\left(40.000,55.000,70.000,85.000\right.$ e 100.000 plantas ha $\left.^{-1}\right)$, no esquema fatorial 2 x 5, avaliados em dois anos agrícolas (2009 e 2010), em cultivo de Inverno-Primavera. O incremento na população de plantas de 40.000 até 100.000 plantas ha $^{-1}$ resultou em maiores produtividades de espigas comerciais despalhadas dos híbridos Tropical Plus e RB-6324. O aumento na população de plantas reduziu o comprimento e o diâmetro de espigas de Tropical Plus e RB-6324, e a massa de espigas de Tropical Plus, mas não afetou o padrão comercial e de uso industrial das mesmas. Em populações de plantas mais elevadas o híbrido RB-6324 produziu espigas com grãos mais adocicados e com menor conteúdo de amido. O híbrido Tropical Plus apresentou maiores massa, comprimento, produtividade, conteúdo de açúcares totais, e menor diâmetro de espigas do que o RB-6324.
\end{abstract}

Palavras-chave: Zea mays L., milho especial, densidade populacional, produtividade, atributos químicos de grãos

\footnotetext{
Abstract

The objective of this study was to evaluate the plant population density effect upon yield components and the chemical composition of grains in two sweet corn hybrids in "Winter-Spring" cultivation. The experimental design used was the complete randomized blocks with four replications. The treatments were based on the combination between two sweet corn hybrids (Tropical Plus e RB-6324) and five plant populations $\left(40,000,55.000,70,000,85,000\right.$ and 100,000 plants ha $\left.{ }^{-1}\right)$, in a factorial scheme $2 \times 5$, evaluated in two "winter-spring" growing seasons (2009 and 2010). The increment in the population of 40,000 to 100,000 plants ha ${ }^{-1}$ resulted in higher husked commercial corn ear productivity in both hybrids, Tropical Plus and RB-6324. The increase of plant population reduced the length and diameter

${ }^{1}$ Eng $^{0}$ Agr ${ }^{\circ}$, Discente de Doutorado em Agronomia, Programa de Pós-graduação em Agronomia, PGA, Universidade Estadual de Maringá, UEM, Maringá, PR. E-mail: nansoares86@hotmail.com

${ }^{2}$ Eng $^{\circ \mathrm{s}} \mathrm{Agr}^{\circ \mathrm{s}}$, Profs. Drs., UEM, Maringá, PR. E-mail: vidigalfilhop@gmail.com; cascapim@uem.br; ojmarques@gmail.com

${ }^{3}$ Enga $^{\text {a }}$ gr $^{\mathrm{a}}$, Discente de Doutorado em Ciências Agrárias, Programa de Pós-graduação em Ciências Agrárias, Universidade Federal do Recôncavo da Bahia, UFRB, Cruz das Almas, BA. E-mail: dyanecq@hotmail.com

${ }^{4}$ Eng $^{\text {o }}$ Agr ${ }^{\text {o }}$, Prof. Dr., Universidade Federal Rural da Amazônia, UFRA, Capitão Poço, PA. E-mail: ricardo_okumura@hotmail. com

${ }^{5}$ Eng $^{\mathrm{o}}$ Agr ${ }^{\mathrm{o}}$, UEM, Maringá, PR. E-mail: deividreche@gmail.com

${ }^{6} \mathrm{Eng}^{\mathrm{o}} \mathrm{Agr}^{\mathrm{o}}$, Discente de Mestrado em Agronomia, PGA, UEM, Maringá, PR. E-mail: viniciuscortinove@hotmail.com

${ }^{*}$ Autor para correspondência
} 
of corn ears in Tropical Plus and RB-6324. The mass of the corn ears from Tropical Plus also reduced; however, it did not affect the commercial standard and industrial use. In larger plant populations the hybrid RB-6324 produced corn ears with grains that were sweeter and with lower starch content. The hybrid Tropical Plus presented higher mass, length, productivity, sugar content and lower diameter of corn ears when compared to RB-6324.

Key words: Zea mays L., special corn, population density, yield, chemical attributes of grains

\section{Introdução}

Os cultivares de milho, pertencentes à espécie Zea mays $\mathrm{L}$., e que contém alelos recessivos mutantes tais como shrunken-2 (sh2), brittle (bt), sugary enhancer (se), sugary ( $s u$ ) e brittle-2 (bt2), que afetam a biossíntese de carboidratos no endosperma dos grãos (OLIVEIRA JÚNIOR et al., 2007) são conhecidos como milho doce e super doce (PARENTONI et al., 1990). Enquanto o milho comum apresenta em torno de $3 \%$ de açúcar e entre 60 e $70 \%$ de amido, o milho doce tem em torno de 9 a $14 \%$ de açúcar e 30 a $35 \%$ de amido, e o superdoce tem em torno de $25 \%$ de açúcar e 15 a $25 \%$ de amido (PEREIRA FILHO; CRUZ; GAMA, 2003).

Os dados estatísticos de produção de milho doce são escassos uma vez que eles são apresentados em conjunto à produção de milho verde, que na maioria das vezes, advém de lavouras de milho comum. De acordo com FAO (2013), a área mundial cultivada com o milho verde no ano de 2011 foi de 1.083 .680 ha, com a produção global alcançando 9.111 .763 $\mathrm{Mg}$ de espigas. Neste tipo de exploração comercial de milho destacam-se os Estados Unidos (40,14\%), Nigéria $(8,12 \%)$ e o México $(7,38 \%)$, com uma produção de 3.657.550; 740.000 e $672.311 \mathrm{Mg}$ de espigas verdes.

O Brasil, um dos principais produtores mundiais de milho comum, também apresenta produção e consumo de milho verde e de milho doce, embora os dados não sejam contabilizados (USDA, 2010). Tanto o Brasil quanto o Paraná, principal produtor brasileiro de milho comum, possuem potencial para aumentar a àrea cultivada com milho doce (WILLIAMS, 2012; MARTIN et al., 2011), e na atualidade, este seguimento apresenta tendência de crescimento, devido principalmente a exportação (BARBIERI et al., 2005).

Dessa forma, a exploração do milho doce pode constituir-se em alternativa econômica tanto para os hortigranjeiros dos cinturões verdes das grandes metrópoles, especialmente os agricultores familiares que produzem milho para consumo in natura, como para aqueles de locais mais distantes com produção de milho destinado ao processamento industrial (ZÁRATE et al., 2009).

Entre os fatores que contribuem para a obtenção de maiores produtividades tanto de milho comum quanto de milho doce destaca-se a utilização de elevadas populações de plantas (SANGOI et al., 2005), que podem ser ajustadas por meio da alteração do espaçamento entre as linhas bem como pelo aumento da densidade de plantas nas linhas de semeadura (SILVA et al., 2007). As características apresentadas pelos híbridos modernos de milho tais como ciclo mais curto, porte mais baixo e menor número de folhas por planta (STRIEDER et al., 2007), podem resultar em incremento no potencial de resposta desses híbridos, geralmente híbridos simples, com o aumento na população de plantas (BARBIERI et al., 2005; SANGOI et al., 2005; SILVA et al., 2010), devido ao favorecimento da interceptação da radiação solar (KVITSCHAL et al., 2010).

Entretanto, é necessário ressaltar que para o milho doce o comprimento e o diâmetro das espigas devem ser adequados ao processamento industrial (ALBUQUERQUE et al., 2008), uma vez que o padrão comercial aceita somente espigas maiores 
que $15 \mathrm{~cm}$ de comprimento e de $3 \mathrm{~cm}$ de diâmetro, por aumentarem a eficiência das máquinas industriais degranadoras. Além disso, espigas bem granadas, com maior massa (BARBIERI et al., 2005; SANGOI et al., 2005), também são desejáveis (ALBUQUERQUE et al., 2008).

No caso do milho verde doce o conteúdo de carboidratos tais como sacarose e frutose, e de amido, definem atributos de qualidade sendo de extrema importância sua investigação, quando se visa melhorar a recomendação ao produtor e a aceitação do consumidor (CANIATO et al., 2004).

Os produtores de milho doce frequentemente utilizam recomendações de populações de plantas sugeridas para o milho comum, as quais nem sempre são as ideais para esse tipo de cultivo. Neste contexto, considerando a importância do milho doce, e a carência de informações para a região Noroeste do Paraná, objetivou-se avaliar os efeitos da população de plantas sobre os componentes da produção e a composição química de grãos de híbridos de milho doce, no cultivo de "Inverno Primavera".

\section{Material e Métodos}

O presente trabalho foi constituído de dois experimentos de campo conduzidos no período de “Inverno - Primavera”, dos anos agrícolas de 2009 (28 de agosto a 27 de novembro) e de 2010 (9 de setembro a 20 de dezembro). A área experimental localiza-se no Distrito de Iguatemi, Maringá, região Noroeste do Paraná, latitude $23^{\circ} 20^{\prime} 48^{\prime \prime}$ S e longitude $52^{\circ} 04^{\prime} 17^{\prime \prime} \mathrm{W}$, com altitude aproximada de 510 m. O clima de Maringá é do tipo Cfa, ou seja, subtropical, conforme classificação de Köppen. Os dados climatológicos, tais como as médias de precipitação pluvial e das temperaturas máximas e mínimas durante os períodos experimentais estão apresentados na Figura 1.

Figura 1. Precipitação pluvial e temperaturas médias, máximas e mínimas ocorridas durante o período experimental dos anos agrícolas de 2009 (13 semanas) e 2010 (15 semanas).

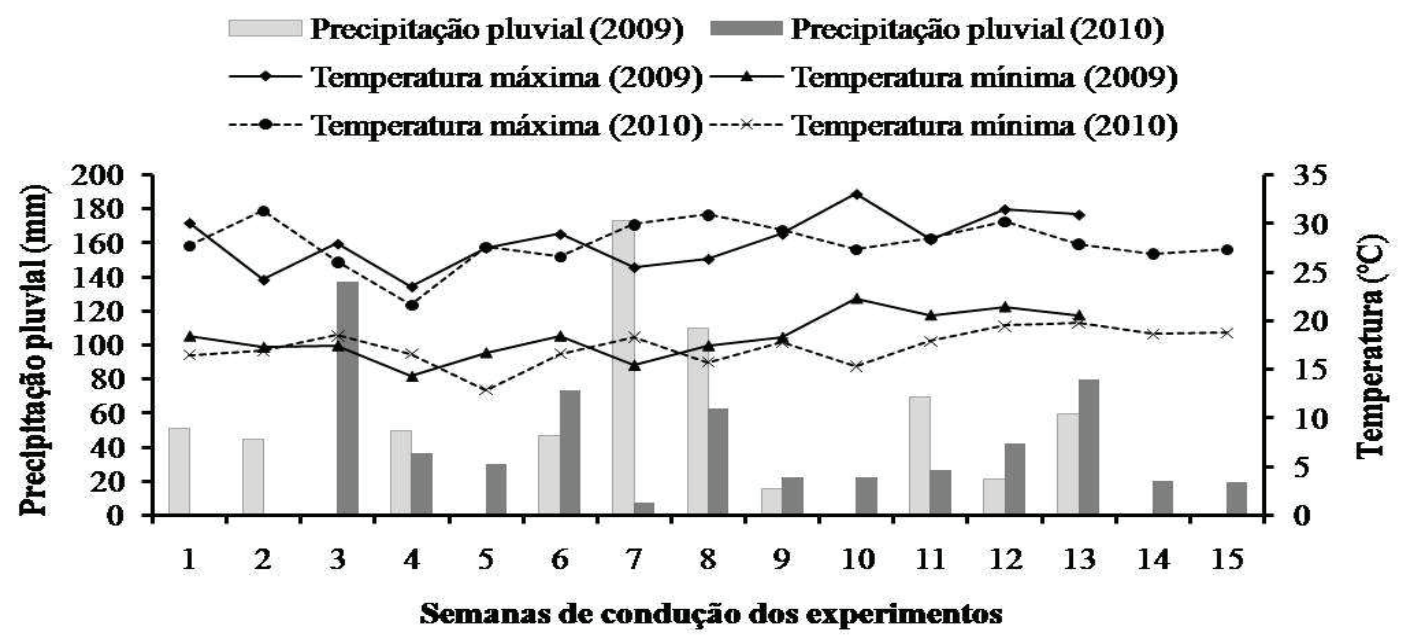

Fonte: Elaboração dos autores. 
O solo da área experimental utilizado para realização dos experimentos caracteriza-se por ser um Nitossolo Vermelho distroférrico, de textura argilosa (EMBRAPA, 2006). Os resultados das análises químicas foram, em 2009 e 2010, respectivamente: $\mathrm{pH}$ em $\mathrm{CaCl}_{2}=5,0$ e 4,6; $\mathrm{C}=$ 11,86 e $9,68 \mathrm{~g} \mathrm{~kg}^{-1} ; \mathrm{P}=10,0$ e $8,3 \mathrm{mg} \mathrm{dm}{ }^{-3} ; \mathrm{Al}^{3+}=$ 0,01 e $0,1 \mathrm{cmol}_{\mathrm{c}} \mathrm{dm}^{-3} ; \mathrm{Al}^{3+}+\mathrm{H}^{+}=3,87$ e $3,69 \mathrm{cmol}_{\mathrm{c}}$ $\mathrm{dm}^{-3} ; \mathrm{Ca}^{2+}=4,25$ e $3,27 \mathrm{cmol}_{\mathrm{c}} \mathrm{dm}^{-3} ; \mathrm{Mg}^{2+}=1,66 \mathrm{e}$ $1,21 \mathrm{cmol}_{\mathrm{c}} \mathrm{dm}^{-3} ; \mathrm{K}^{+}=0,52$ e $0,30 \mathrm{cmol}_{\mathrm{c}} \mathrm{dm}^{-3} ; \mathrm{SB}=$ 6,43 e $4,78 \mathrm{cmol}_{c} \mathrm{dm}^{-3}$; CTC $=10,30$ e $8,47 \mathrm{cmol}_{\text {c }}$ $\mathrm{dm}^{-3}$ e $\mathrm{V}=62,43$ e $56,43 \%$.

No início do mês de junho de 2010, considerando os resultados das análises químicas de material de solo, e conforme recomendações de Raij et al. (1996), procedeu-se a calagem da área experimental com a aplicação de $1,5 \mathrm{Mg} \mathrm{ha}^{-1}$ de calcário dolomítico (PRNT 80\%).

Os tratamentos foram delineados em blocos completos casualizados, com quatro repetições, num esquema fatorial de $2 \times 5$, resultante da combinação de dois híbridos de milho doce e superdoce: Tropical Plus e RB-6324, ambos precoces, simples e superdoces; com cinco populações de plantas (40.000, 55.000, 70.000, 85.000 e 100.000 plantas $\left.\mathrm{ha}^{-1}\right)$. As unidades experimentais foram compostas por 5 linhas de plantas de $6,0 \mathrm{~m}$ de comprimento, espaçadas de $0,90 \mathrm{~m}$, sendo a área útil representada pelas 3 linhas centrais, excluindo-se $0,5 \mathrm{~m}$ de cada extremidade da parcela, perfazendo uma área útil de $13,5 \mathrm{~m}^{2}$.

Aos sete dias anteriores à semeadura (présemeadura), procedeu-se a dessecação das plantas daninhas existentes na área experimental, utilizando-se a dose de $0,960 \mathrm{~kg}$ de ingrediente ativo (i.a.) ha ${ }^{-1}$ do herbicida glyphosate (ANDREI, 2005). Por sua vez, a adubação de semeadura, segundo recomendações de Raij et al. (1996), constituiu-se da aplicação de 20, 80 e $60 \mathrm{~kg}$ de N, $\mathrm{P}_{2} \mathrm{O}_{5}$ e $\mathrm{K}_{2} \mathrm{O}$ ha' 1 , nas formas de Sulfato de Amônio, Superfosfato Triplo e Cloreto de Potássio, respectivamente.
$\mathrm{Na}$ implantação dos experimentos utilizou-se de semeadora manual (matraca), distribuindose duas sementes por cova. As populações de plantas utilizadas foram ajustadas por meio dos espaçamentos entre plantas na linha de semeadura. Após a emergência das plantas, no estádio $\mathrm{V}_{2}$ (RITCHIE; HANWAY; BENSON, 1993), efetuouse o desbaste, deixando-se somente uma planta por cova. Em ambos os períodos de cultivo, a adubação nitrogenada de cobertura foi realizada no estádio $\mathrm{V}_{4}$ (RITCHIE; HANWAY; BENSON, 1993), utilizando-se $90 \mathrm{~kg}$ de $\mathrm{N} \mathrm{ha}^{-1}$ na forma de Sulfato de Amônio (EMBRAPA, 2011).

Ao longo dos experimentos, nos dois anos agrícolas de avaliação, e com o objetivo de evitar estresse hídrico às plantas de milho doce, foi utilizada irrigação por aspersão, de modo a garantir a suplementação de água à cultura. As pragas iniciais comuns à cultura do milho doce tais como percevejo-barriga-verde (Dichelops spp.) larvaalfinete (Diabrotica speciosa Germar, 1824); e lagarta-elasmo (Elasmopalpus lignosellus Zeller, 1848) foram controladas mediante a aplicação de $0,240+0,700 \mathrm{~kg}$ de $\mathrm{kg}$ de i.a. $\mathrm{ha}^{-1}$ dos inseticidas imidacloprido + tiodicarbe, por $100 \mathrm{~kg}$ de sementes. Por sua vez, o controle de lagarta-do-cartucho (Spodoptera frugiperda Smith, 1797) e de lagartada-espiga (Helicoverpa zea Boddie, 1850) foi efetuado com a aplicação de $0,300 \mathrm{~kg}$ e de 0,015 $\mathrm{kg}$ de i.a. ha-1, respectivamente, dos inseticidas methamidophos e lufenuron (ANDREI, 2005). Enquanto que o controle de plantas daninhas foi realizado com a aplicação, em pós-emergência, do herbicida atrazina, na dosagem de $3,25 \mathrm{~kg}$ de i.a. ha $^{-1}$ (ANDREI, 2005).

A colheita foi efetuada manualmente, no estádio $\mathrm{R}_{3}$ ou de grãos leitosos (RITCHIE; HANWAY; BENSON, 1993), sendo avaliados os seguintes componentes de produção: massa média de cinco espigas despalhadas $(\mathrm{kg})$; produtividade média de espigas comerciais despalhadas $\left(\mathrm{kg} \mathrm{ha}{ }^{-1}\right)$; comprimento e diâmetro médio de dez espigas despalhadas (m). Espigas com comprimentos 
e diâmetros maiores que $0,15 \mathrm{~m}$ e $0,30 \mathrm{~m}$, respectivamente, foram consideradas espigas comerciais (ALBUQUERQUE et al., 2008).

Cinco espigas de cada tratamento foram escolhidas, de modo aleatório, despalhadas e submetidas ao processo de branqueamento em água, com temperatura de $100{ }^{\circ} \mathrm{C}$, durante 5 minutos, sendo, em seguida, resfriadas em água com temperatura de $20^{\circ} \mathrm{C}$, durante 10 minutos. Com a finalização do branqueamento, as espigas foram acondicionadas em sacos plásticos, congeladas em freezer com temperatura de $-18{ }^{\circ} \mathrm{C}$ (INSTITUTO ADOLFO LUTZ, 2005).

Por ocasião das análises químicas efetuou-se o descongelamento das espigas, e a seguir, procedeuse a degrana das mesmas. Os procedimentos de secagem e trituração dos grãos, bem como a obtenção de amostras para determinação de carboidratos, foram realizados de acordo com o Instituto Adolfo Lutz (2005). Os atributos químicos dos grãos de milho doce foram avaliados mediante mensuração dos teores de açúcares totais (\%) e amido (\%), determinados pelo método de LaneEynon, segundo os métodos físico-químicos para análises de alimentos do Instituto Adolfo Lutz (2005).

Os dados experimentais foram submetidos à análise de variância individual, considerando o nível de probabilidade de $\mathrm{F}$ de $5 \%$, visando à estimação dos quadrados médios do resíduo, que, por sua vez, foram submetidos ao teste do $\mathrm{F}$ máximo de Hartley (BANZATTO; KRONKA, 2006). Uma vez verificada a homogeneidade entre os quadrados médios individuais, o efeito da população de plantas foi avaliado por meio da análise de regressão polinomial, e o efeito dos híbridos pelo teste $\mathrm{F}$ $(p<0,05)$ (CRUZ; REGAZZI, 2001). No caso em que não foi possível o ajuste por modelos lineares e nãolineares, a variável resposta foi analisada por meio da estatística descritiva (média e desvio padrão). As análises estatísticas foram realizadas mediante uso do programa estatístico Sisvar (FERREIRA, 2000).

\section{Resultados e Discussão}

$\mathrm{Na}$ análise de variância conjunta da massa média de espigas despalhadas verificou-se significância para o fator ano agrícola, assim como para a interação entre população de plantas x ano agrícola, enquanto os demais fatores e interações não foram significativos (Tabela 1). Embora o desdobramento da interação tripla não tenha sido significativo, para o híbrido Tropical Plus, nos dois anos agrícolas, foram obtidas equações de regressão significativas, que explicam o comportamento da massa média de espigas despalhadas em função do aumento na população de plantas (Figura 2a). O mesmo não ocorreu com híbrido RB-6324, em ambos os anos agrícolas (Tabela 1 e Figura 2a).

Em 2009, o híbrido Tropical Plus apresentou massa média de espiga despalhada, máxima estimada, em 200,46 g na população de plantas de 71.371 plantas ha $^{-1}$, (Figura 2a). Já no ano de 2010, para o mesmo híbrido, houve decréscimo linear de 5,61 g na massa média de espiga despalhada para cada incremento de 10.000 plantas ha $^{-1}$ (Figura 2a).

Em estudo desenvolvido por Rocha (2008) com diferentes cultivares de milho comum (milho verde) foi observado comportamento quadrático semelhante ao obtido para Tropical Plus em 2009, entre 30.000 a 60.000 plantas ha $^{-1}$, quanto à massa de espigas despalhadas por área, concordando com o reportado por Cruz e Pereira Filho (2003). Semelhanças também foram encontradas para o híbrido Tropical Plus em 2010, observando-se reduções lineares da massa de espigas despalhadas com o aumento na densidade de plantas. 
Tabela 1. Resumo da análise de variância conjunta (quadrados médios) referente à massa média de espigas despalhadas (MED), produtividade média de espigas comerciais despalhadas (PECD) e comprimento médio de espigas (CE) de dois híbridos de milho doce em cinco populações de plantas e dois anos agrícolas.

\begin{tabular}{|c|c|c|c|}
\hline \multirow{2}{*}{ Fonte de variação } & \multicolumn{3}{|c|}{ Características } \\
\hline & MED (kg) & $\operatorname{PECD}\left(\mathrm{kg} \mathrm{ha}^{-1}\right)$ & $\mathrm{CE}(\mathrm{m})$ \\
\hline População de Plantas (P) & $0,006045^{\text {ns }}$ & $3.830 .118^{*}$ & $1,38110^{-4^{*}}$ \\
\hline Híbrido (H) & $0,01723^{\mathrm{ns}}$ & $6.186 .613^{*}$ & $1,10210^{-3 \mathrm{~ns}}$ \\
\hline Ano & $0,6391^{*}$ & $481.586^{\mathrm{ns}}$ & $1,22110^{-3 \mathrm{~ns}}$ \\
\hline $\mathrm{P} \times \mathrm{H}$ & $0,01581^{\mathrm{ns}}$ & $122.811^{\mathrm{ns}}$ & $2,62810^{-5 \mathrm{~ns}}$ \\
\hline $\mathrm{H} \times \mathrm{Ano}$ & $0,02738^{\mathrm{ns}}$ & $64.468^{\mathrm{ns}}$ & $4,10510^{-6 n s}$ \\
\hline P x Ano & $0,03895^{*}$ & $1.045 .646^{*}$ & $6,58410^{-6 n s}$ \\
\hline $\mathrm{P} \times \mathrm{H} \times$ Ano & $0,005868^{\text {ns }}$ & $263.751^{\mathrm{ns}}$ & $2,01310^{-5 \mathrm{~ns}}$ \\
\hline $\mathrm{P} / \mathrm{H} 1 \mathrm{Ano} 1$ & $0,01765^{\text {ns }}$ & $690.203^{\mathrm{ns}}$ & $7,74110^{-5 n s}$ \\
\hline P / H2 Ano 1 & $0,01642^{\mathrm{ns}}$ & $911.141^{*}$ & $3,84710^{-5 \mathrm{~ns}}$ \\
\hline $\mathrm{P} / \mathrm{H} 1 \mathrm{Ano} 2$ & $0,02385^{\mathrm{ns}}$ & $2.479 .573^{*}$ & $4,64410^{-5 n s}$ \\
\hline P / H2 Ano 2 & $0,008745^{\text {ns }}$ & $1.181 .409^{*}$ & $2,83210^{-5 \mathrm{~ns}}$ \\
\hline Bloco/Ano & $0,07603^{\text {ns }}$ & $263.716^{\mathrm{ns}}$ & $1,31010^{-5 n s}$ \\
\hline Resíduo & 0,01078 & 318.014 & $5,33210^{-5}$ \\
\hline Média Geral & 0,213 & 6.360 & 0,178 \\
\hline C.V. $(\%)$ & 9,75 & 17,71 & 8,09 \\
\hline
\end{tabular}

*Significativo $(\mathrm{p}<0,05)$ e ns - não significativo (p>0,05), pelo teste F. (H1) Tropical Plus; (H2) RB-6324; (Ano 1): 2009 e (Ano 2): 2010 .

Fonte: Elaboração dos autores.

Figura 2. Massa média de espigas despalhadas (a) e produtividade média de espigas comerciais despalhadas (b) dos híbridos de milho doce Tropical Plus (H1) e RB-6324 (H2), em função da população de plantas, nos anos agrícolas de 2009 (Ano 1) e 2010 (Ano 2). *Significativo $(\mathrm{P}<0,05)$ pelo teste t de Student.

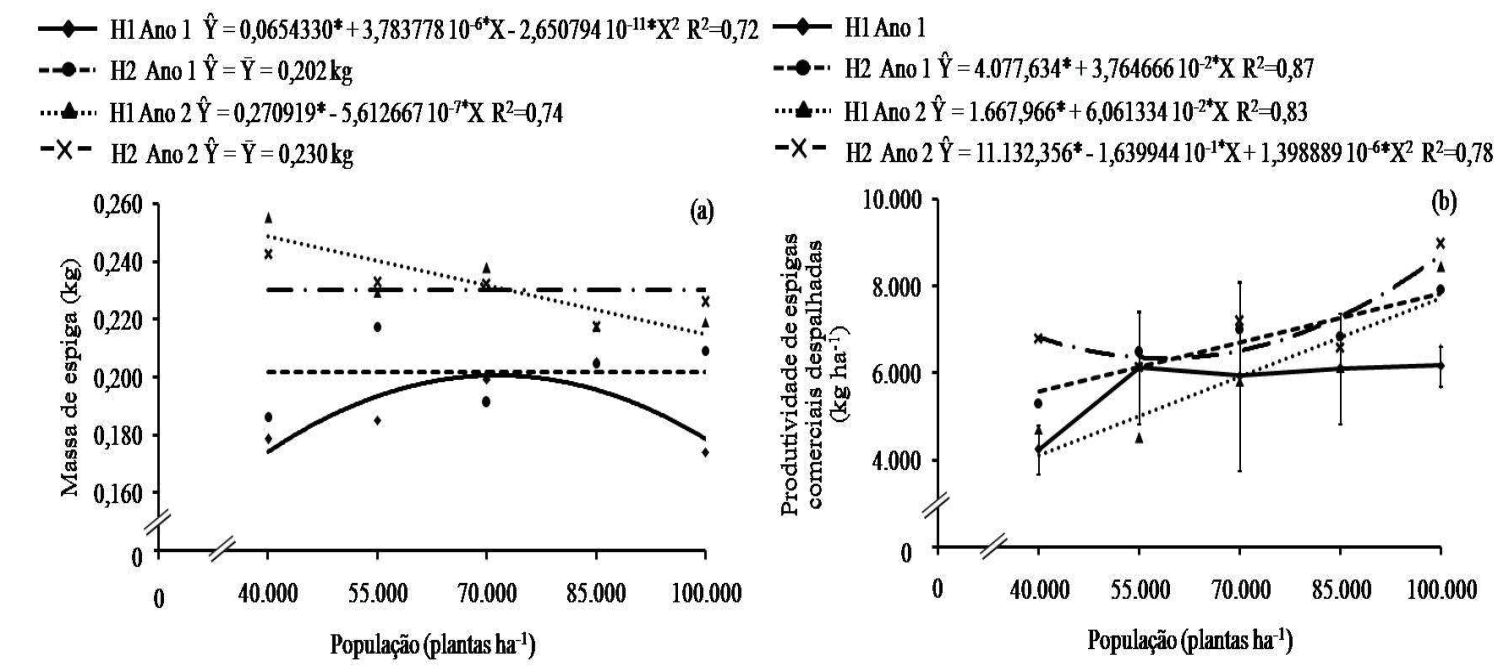

Fonte: Elaboração dos autores. 
O aumento da competição intra-específica, assim como a dominância apical proporcionados pelo incremento na população, impõe mudanças fisiológicas às plantas de milho, que resultam em um menor crescimento e desenvolvimento das espigas, e consequentemente, propiciam redução no acúmulo de fotoassimilados nas espigas (ARGENTA; SILVA; SANGOI, 2001). A redução da massa de grãos, com o aumento na população de plantas, também pode ter sido responsável pela redução da massa de espiga (FLESCH; VIEIRA, 2004; PIANA et al., 2008). Isto ocorre porque o aumento da competição intra-específica, assim como a dominância apical do pendão sobre a espiga (ARGENTA; SILVA; SANGOI, 2001; SANGOI et al., 2002), faz com que a disponibilidade de carboidratos por unidade de grão decresça linearmente com o aumento da população de plantas (SANGOI, 2001).

Nos resultados da análise de variância conjunta, para produtividade média de espigas comerciais despalhadas, os fatores população de plantas e híbrido e a interação entre população de plantas $\mathrm{x}$ ano agrícola foram significativos (Tabela 1). Embora a interação tripla não tenha sido significativa o seu desdobramento evidenciou efeitos significativos da população de plantas dentro de híbrido e ano agrícola (Tabela 1), com ajustes de regressão polinomiais (Figura 2b).

No ano agrícola de 2009, para o híbrido RB6324, a produtividade média de espigas comerciais despalhadas cresceu linearmente em função do aumento na população de plantas, com incremento de $0,38 \mathrm{t} \mathrm{ha}^{-1}$ a cada 10.000 plantas ha-1 adicionadas (Figura 2b). Por sua vez, não foi obtido ajuste significativo de modelos lineares e não-lineares para Tropical Plus, no ano agrícola de 2009. Entretanto, foi possível observar, por meio da estatística descritiva, que com aproximadamente 55.000 plantas ha ${ }^{-1}$ ocorreu estabilização da produtividade média de espigas comerciais despalhadas, em torno de 6,0 $\mathrm{tha}^{-1}$ (Figura 2b).
No ano de 2010 observaram-se ajustes significativos para a produtividade média de espigas comerciais despalhadas em função do incremento na população de plantas, sendo que, para híbrido Tropical Plus, a resposta foi linear crescente, com incremento de $0,60 \mathrm{t} \mathrm{ha}^{-1}$ a cada 10.000 plantas ha $^{-1}$ acrescidas à população de plantas (Figura 2b). Enquanto que, para o híbrido RB-6324, a resposta se ajustou ao modelo quadrático com a menor produtividade média de espigas comerciais despalhadas, estimada em 6,32 $\mathrm{t} \mathrm{ha}^{-1}$, encontrada na

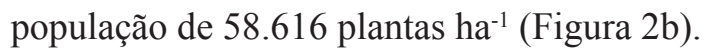

O milho doce apresenta baixa plasticidade produtiva, ou seja, não possui capacidade de compensar a produtividade em menor número de plantas por área (BARBIERI et al., 2005). Desta forma, quando se deseja uma maior produtividade de milho doce, um maior número de plantas por área deve ser utilizado, para haver compensação no rendimento, assim como relatado para milho comum (FLESCH; VIEIRA, 2004; BRACHTVOGEL et al., 2009). Este fato, associado, de modo geral, às boas condições climáticas (SANGOI et al., 2001; KVITSCHAL et al., 2010) observadas no período de condução dos experimentos (Figura 1), além da adequada irrigação e fertilização do solo, pode ter contribuído para os incrementos de produtividade média de espigas comerciais despalhadas observados no presente estudo (Figura 2b).

Kvitschal et al. (2010), utilizando o espaçamento de 0,90 m e híbrido de milho comum DKB 234, observaram que o comportamento da produtividade de grãos, em função da população de plantas, foi linear crescente, considerando-se o segundo ano agrícola avaliado. Segundo os autores, essa resposta, provavelmente, deveu-se às condições ambientais favoráveis ocorridas no segundo ano agrícola, conforme discutido por Sangoi et al. (2001). Da mesma forma que Kvitschal et al. (2010), Silva et al. (2010) constataram para o híbrido de milho comum D 2B587, sob irrigação, incremento linear de 0,6 tha $^{-1}$ a cada 10.000 plantas ha $^{-1}$ acrescidas à população de plantas. 
Considerando o espaçamento entre linhas $(0,9$ m) e os híbridos utilizados, é válido afirmar que nas condições do presente estudo, possivelmente, a precocidade dos híbridos não proporcionou sombreamento intra-específico suficiente, que fosse capaz de afetar negativamente a produtividade média de espigas despalhadas. Embora a época de semeadura ideal para milho no estado do Paraná, como Safra de "Verão", seja de 11 de setembro a 20 de novembro, as semeaduras antecipadas são consideradas precoces (CARAMORI et al., 1999), como foi o caso neste estudo, especialmente no ano de 2009.

Nas semeaduras precoces podem ser requeridas maiores densidades, como estratégia para compensar o menor desenvolvimento vegetativo das plantas, devido às menores disponibilidades térmicas e de radiação solar durante o período vegetativo (PIANA et al., 2008). Assim, é possível afirmar que a época de semeadura precoce, possivelmente, contribuiu no aumento da produtividade média de espigas despalhadas, com o aumento da população de plantas (Figura 2b), especialmente em virtude dos ciclos dos híbridos utilizados também serem precoces.
Em relação ao comprimento médio de espigas a análise de variância conjunta evidenciou o efeito significativo somente do fator população de plantas (Tabela 1). A interação tripla entre população de plantas x híbrido $\mathrm{x}$ ano agrícola não apresentou efeito significativo, tão pouco seu desdobramento (Tabela 1). Todavia, no ano de 2009, constatouse um ajuste linear decrescente significativo do comprimento médio de espiga, em função das densidades populacionais, para híbrido Tropical Plus, com redução de $0,16 \mathrm{~cm}$, a cada acréscimo de 10.000 plantas ha $^{-1}$ à população (Figura 3a). Nos demais casos não houve ajustes significativos que explicassem o comportamento da variável resposta avaliada em função do aumento na densidade de plantas. Entretanto, os valores médios estimados de comprimento de espigas (Figura 3a) foram todos superiores ao exigido pelo padrão comercial $(>15$ $\mathrm{cm}$ ), conforme (ALBUQUERQUE et al., 2008). De acordo com Pereira Filho, Cruz e Gama (2003) espigas de maior tamanho conferem maior eficiência das máquinas degranadoras na retirada dos grãos inteiros das espigas nas indústrias de processamento do milho doce.

Figura 3. Comprimento médio de espigas (a) e diâmetro médio de espigas (b) dos híbridos de milho doce Tropical Plus (H1) e RB-6324 (H2), em função da população de plantas nos anos agrícolas de 2009 (Ano 1) e 2010 (Ano 2). *Significativo $(\mathrm{p}<0,05)$ pelo teste $t$ de Student.
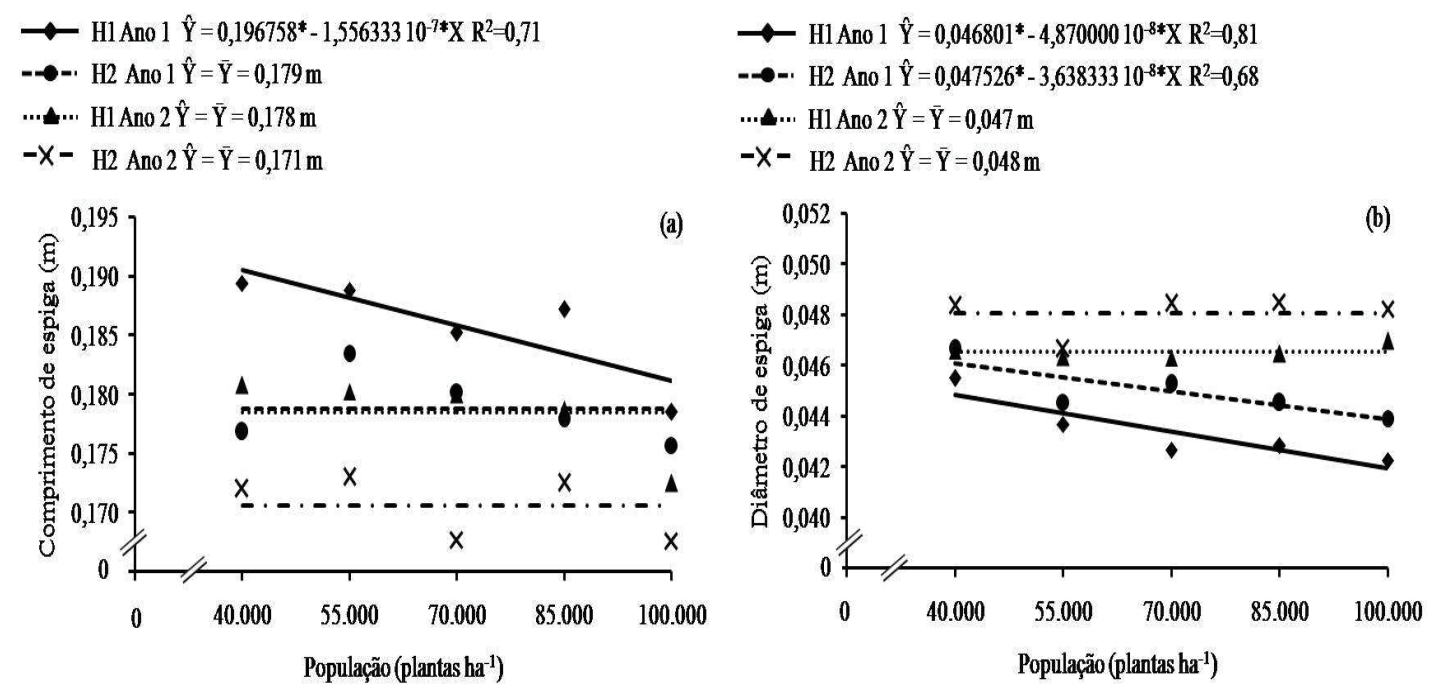

Fonte: Elaboração dos autores. 
O resultado obtido com o híbrido Tropical Plus, em 2009, assemelha-se àqueles de Barbieri et al. (2005), que estudando cinco densidades populacionais, variando de 50.000 a 70.000 plantas ha $^{-1}$, em dois híbridos de milho superdoce (MD2001 e MD2002), verificaram que houve decréscimo de $0,6 \mathrm{~cm}$ no comprimento médio de espigas, conforme o aumento gradual de 10.000 plantas ha $^{-1}$.

Resultados obtidos por Brachtvogel et al. (2009) permitiram associar o decréscimo do comprimento de espiga com a maior competição intra-específica por luz, água e nutrientes, em maiores densidades populacionais (ARGENTA; SILVA; SANGOI, 2001). Entretanto, é necessário destacar que as mudanças fisiológicas, de natureza hormonal, impostas às plantas, influenciam significativamente a redução do comprimento de espiga. Isto ocorre devido ao estímulo à dominância apical, que prioriza o transporte de substâncias, como água, fotoassimilados, fitormônios, assim como os nutrientes, para o crescimento e desenvolvimento do pendão, localizado no ponto de crescimento das plantas, em detrimento das espigas. Estas crescem e se desenvolvem menos, tornando-se, portanto, menores (SANGOI et al., 2002).

A análise de variância conjunta dos dados de diâmetro médio de espiga evidenciou efeitos significativos dos fatores isolados, bem com da interação entre população de plantas x ano agrícola (Tabela 2). A interação tripla não foi significativa, porém no desdobramento desta interação, observouse efeito significativo da população de plantas dentro de híbrido e ano agrícola. Embora tenha sido observado desdobramento significativo apenas para o híbrido Tropical Plus em 2009 (Tabela 2), ambos os híbridos tiveram valores ajustados à regressão linear decrescente, em função da população de plantas, com redução de 0,05 e $0,04 \mathrm{~cm}$, para os híbridos Tropical Plus e RB-6324, respectivamente, a cada acréscimo de 10.000 plantas ha ${ }^{-1}$ à população (Figura 3b). Por outro lado, no ano de 2010, o diâmetro médio de espigas comportou-se de maneira constante, apenas com variações do acaso (Figura 3b).

Tabela 2. Resumo da análise de variância conjunta (quadrados médios) referente ao diâmetro médio de espigas (DE), conteúdo médio de açúcares totais (AT) e de amido (AM) de dois híbridos de milho doce em cinco populações de plantas e dois anos agrícolas.

\begin{tabular}{llcc}
\hline \multirow{2}{*}{ Fonte de variação } & \multicolumn{3}{c}{ Características } \\
\cline { 2 - 4 } & DE $(\mathrm{m})$ & AT $(\%)$ & AM $(\%)$ \\
\hline População de Plantas $(\mathrm{P})$ & $5,71610^{-6^{*}}$ & $23,6442^{*}$ & $8,5679^{*}$ \\
Híbrido (H) & $4,79310^{-5^{*}}$ & $73,8240^{*}$ & $16,0026^{*}$ \\
Ano & $1,91210^{-4^{*}}$ & $15,9222^{*}$ & $0,781^{\mathrm{ns}}$ \\
P x H & $1,69510^{-6 \mathrm{~ns}}$ & $39,3850^{*}$ & $5,0546^{*}$ \\
H x Ano & $3,40210^{-8 \mathrm{~ns}}$ & $3,9739^{\text {ns }}$ & $9,9828^{*}$ \\
P x Ano & $5,98410^{-6^{*}}$ & $3,5531^{*}$ & $1,4128^{*}$ \\
P x H x Ano & $2,95610^{-7 \mathrm{~ns}}$ & $3,3264^{*}$ & $0,9960^{\mathrm{ns}}$ \\
\hline P / H1 Ano 1 & $6,60910^{-6^{*}}$ & $1,7558^{\mathrm{ns}}$ & $1,1556^{\mathrm{ns}}$ \\
P / H2 Ano 1 & $4,35210^{-6 \mathrm{~ns}}$ & $18,4264^{*}$ & $7,2702^{*}$ \\
P / H1 Ano 2 & $3,01410^{-7 \mathrm{~ns}}$ & $2,1629^{\mathrm{ns}}$ & $1,1110^{\mathrm{ns}}$ \\
P / H2 Ano 2 & $2,42310^{-6 \mathrm{~ns}}$ & $47,5634^{*}$ & $6,4945^{*}$ \\
\hline Bloco/Ano & $6,07910^{-6^{*}}$ & $1,8867^{\mathrm{ns}}$ & $0,6005^{\mathrm{ns}}$ \\
Resíduo & $1,89110^{-6}$ & 1,2715 & 0,4874 \\
\hline Média Geral & 0,0457 & 27,10 & 16,22 \\
\hline C.V. (\%) & 3,01 & 4,16 & 4,30 \\
\hline
\end{tabular}

*Significativo $(\mathrm{p}<0,05)$ e ns - não significativo ( $>0$ 0,05), pelo teste F. (H1) Tropical Plus; (H2) RB-6324; (Ano 1): 2009 e (Ano 2): 2010.

Fonte: Elaboração dos autores. 
Em 2009, para o híbrido Tropical Plus, os valores médios de diâmetro de espigas variaram de 4,19 a $4,48 \mathrm{~cm}$, enquanto que para o RB6324, eles situaram-se entre 4,39 $\mathrm{cm}$ e $4,61 \mathrm{~cm}$, aproximadamente. Em 2010, a média da variável resposta foi 4,65 e 4,80 cm, para Tropical Plus e RB-6324, respectivamente. Assim, esses valores de diâmetro permaneceram dentro do padrão comercial $(>3 \mathrm{~cm})$ para espigas de milho doce (ALBUQUERQUE et al., 2008).

Uma redução de $0,09 \mathrm{~cm}$, no diâmetro de espiga, com a adição gradual de 10.000 plantas ha $^{-1}$, no intervalo entre 50.000 e 70.000 plantas ha $^{-1}$, para os híbridos de milho superdoce (MD2001 e MD2002), foi constatada por Barbieri et al. (2005), assemelhando-se aos resultados obtidos em 2009, pelo presente estudo. As semelhanças também são observadas quando nota-se que os valores médios de diâmetro de espigas estiveram entre 4,9 cm e 4,7 $\mathrm{cm}$, aproximadamente, permanecendo dentro do padrão comercial para espigas de milho doce, de acordo com Paiva Júnior et al. (2001).

No ano agrícola de 2009, o comportamento do diâmetro foi semelhante ao observado para o comprimento de espigas, no mesmo ano, para Tropical Plus. Desta forma, pode-se inferir que as causas da redução do comprimento de espigas podem ser as mesmas do decréscimo no seu diâmetro. Segundo Brachtvogel et al. (2009) a menor disponibilidade de recursos do meio para cada planta, com o incremento populacional, decorrente da maior competição entre os indivíduos na lavoura, é uma das possíveis causas da formação de espigas menores. Todavia, assim como para o comprimento de espigas, a dominância apical gerada no pendão, e que leva à prioridade na drenagem de fotoassimilados e de outras substâncias, proporciona um menor crescimento e desenvolvimento das espigas, as quais se tornam menores, tanto em comprimento quanto em diâmetro (SANGOI et al., 2002).
Em populações maiores a situação é agravada pelo sombreamento das folhas baixeiras que se tornam drenos competidores de fotoassimilados, devido à menor quantidade de radiação solar que recebem (TAIZ; ZEIGER, 2004; ROCHA, 2008). Uma menor área foliar fotossinteticamente ativa, decorrente do aumento na densidade de plantas, leva à menor disponibilidade de fotoassimilados para as espigas e para o enchimento de grãos, conforme reportado e explicado por Sangoi et al. (2002), Taiz e Zeiger (2004) e Valentinuz e Tollenaar (2004), o que pode resultar em espigas com comprimento e diâmetro menores.

Todos os fatores estudados apresentaram efeito significativo sobre o conteúdo médio de açúcares totais nos grãos na análise de variância conjunta dos dados, bem como as interações duplas população de plantas x híbrido e população de plantas x ano agrícola, e a interação tripla população de plantas $\mathrm{x}$ híbrido x ano agrícola (Tabela 2).

O desdobramento da interação tripla evidenciou o efeito significativo da população de plantas dentro do híbrido RB-6324, em ambos os anos agrícola, com ajustes ao modelo quadrático, os quais apresentaram teores máximos de açúcares totais estimados em 30,46 e 30,41\%, nas populações de 89.025 e 98.630 plantas ha $^{-1}$, respectivamente, nos anos de 2009 e 2010 (Figura 4a). Por sua vez, para o híbrido Tropical Plus, a variação nos teores de açúcares totais se deveu ao acaso (Figura 4a).

O conteúdo de açúcares totais nos grãos, na média geral, foi de 27,10\% (Figura 4a), e está de acordo com o relatado por Maggio (2006), de que milho da classe superdoce, como é o caso dos híbridos Tropical Plus e RB-6324, possui em torno de $25 \%$ açúcares totais. Embora esta informação seja conflitante com as proferidas por Laughnan (1953) e Hill (2002), para os quais o milho superdoce deve possuir mais que $30 \%$ de açúcares totais. 
Figura 4. Conteúdo médio de açúcares totais (a) e de amido (b) dos híbridos de milho doce Tropical Plus (H1) e RB6324 (H2), em função da população de plantas, nos anos agrícolas de 2009 (Ano 1) e 2010 (Ano 2). *Significativo $(\mathrm{p}<0,05)$ pelo teste $\mathrm{t}$ de Student.
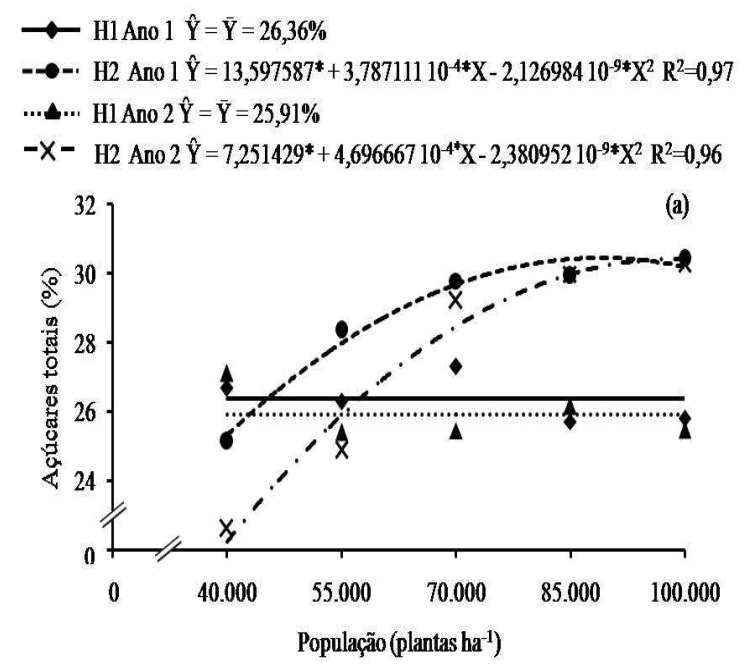

Fonte: Elaboração dos autores.

O aumento da população de plantas proporciona a dominância apical, resultante da maior relação de luz no espectro vermelho distante/vermelho e da menor fotooxidação de auxina no ponto de crescimento das plantas, e que prioriza o transporte de substâncias para o pendão, em detrimento das espigas (SANGOI et al., 2002). Tal mudança fisiológica, juntamente com a maior competição intra-específica por recursos do meio seria, a princípio, a responsável pela redução do conteúdo de açúcares totais em milho doce, devido à redução da disponibilidade de fotoassimilados por planta e espigas, em uma determinada área (ARGENTA; SILVA; SANGOI, 2001).

Um menor acúmulo de massa seca nos grãos, assim como a redução de sua massa total, seriam, desta forma, resultados das alterações provocadas pelo aumento populacional (FLESCH; VIEIRA, 2004; PIANA et al., 2008), devido à menor disponibilidade de açúcares por unidade de grão (SANGOI, 2001).

No milho normal há relação entre umidade, açúcares redutores, sacarose, amido e massa seca

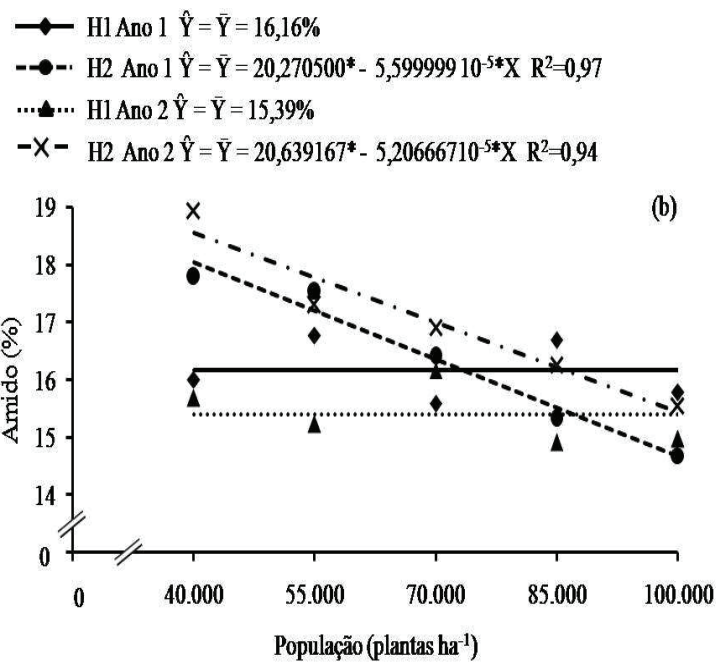

total durante o desenvolvimento do grão. Ou seja, o conteúdo de umidade dos grãos decresce continuamente enquanto que o conteúdo de amido aumenta (CANIATO et al., 2007). Observações semelhantes foram verificadas por Creech (1965), que obteve correlações negativas entre o conteúdo de açúcares totais, açúcares redutores e sacarose com a massa seca e o amido, indicando que os açúcares são precursores do amido. No milho normal, Creech (1968) descreveu que os açúcares totais aumentam até o $15^{\circ}$ dia após a polinização, e decrescem durante o amadurecimento, devido ao posterior aumento do conteúdo de amido.

Diante do fato do milho verde doce ser colhido com uma umidade maior que a do milho normal, entre 70 a 80\% (PEREIRA; CRUZ; GAMA, 2003), é válido dizer que na colheita, o conteúdo de açúcares totais, sejam eles redutores (glucose e frutose) ou não-redutores, seja significativamente maior que o de amido (KWIATKOWSKI, 2007).

A análise de variância conjunta dos dados de conteúdo de amido nos grãos indicou efeito significativo dos fatores população de plantas e 
híbrido e das interações duplas, enquanto o fator ano agrícola e a interação tripla não foram significativos (Tabela 2). Ainda que a interação tripla tenha sido não significativa, foi detectado o efeito significativo, no desdobramento da população de plantas dentro do híbrido RB-6324, em ambos os anos agrícolas, com ajuste ao modelo linear decrescente. Observouse que a cada 10.000 plantas ha $^{-1}$ acrescidas à população de milho doce houve uma redução estimada de 0,60 e $0,52 \%$ no conteúdo de amido nos grãos (Figuras 4b).

A média geral conjunta de conteúdo de amido nos grãos foi de 16,22\% (Quadro 29), resultado que encontra-se em concordância com os valores de 15 a 25\% apresentados por Pereira Filho e Cruz (2002) e Maggio (2006), e de 8 a 24\% apresentados por Laughnan (1953) e Wolf (1962), para conteúdo de amido em grãos de milho superdoce.

Os resultados apresentados indicaram relação entre açúcares totais e amido, em função do aumento na população de plantas. Conforme reportado por Caniato et al. (2007), há uma relação negativa, isto é, o aumento do conteúdo de açúcares totais impõe a redução do conteúdo de amido, e vice-versa. Dessa forma, é possível afirmar que a biossíntese de amido a partir dos açúcares precursores no endosperma dos grãos (CREECH, 1965, 1968), foi reduzida com o incremento na população de plantas (Figura 4). Portanto, provavelmente, assim como para o milho normal, o maior conteúdo de açúcares totais deve estar associado a uma menor quantidade de amido acumulado no endosperma, especialmente em função do aumento no número de plantas por área (CREECH, 1965, 1968). Este fato é agravado naturalmente pelo menor conteúdo de amido em milho doce, uma vez que as expressões dos alelos mutantes limitam a biossíntese de amido nos grãos deste tipo especial de milho (MAGGIO, 2006).

$\mathrm{Na}$ comparação entre híbridos foi observada superioridade de RB-6324 sobre Tropical Plus para massa de espigas despalhadas (55.000 plantas ha-1 dentro de 2009; 100.000 plantas ha $^{-1}$ dentro de 2009) e produtividade de espigas comerciais despalhadas (70.000 plantas ha-1 dentro 2009; 100.000 plantas ha $^{-1}$ dentro de 2009; 40.000 plantas ha-1 dentro de 2010; 55.000 plantas ha $^{-1}$ dentro de 2010) (Tabela 3).

Tabela 3. Desdobramento do efeito dos híbridos Tropical Plus (H1) e RB-6324 (H2) em função da população de plantas $(\mathrm{P})$ e do ano $(\mathrm{A})$, referente às características massa média de espigas despalhadas (MED), produtividade média de espigas comerciais despalhadas (PECD) e comprimento médio de espiga (CE).

\begin{tabular}{|c|c|c|c|c|c|c|c|}
\hline \multirow{3}{*}{$\begin{array}{c}\mathrm{P} \\
\left(\text { plantas ha-1) }^{-1}\right)\end{array}$} & \multirow{3}{*}{ A } & \multicolumn{6}{|c|}{ Características } \\
\hline & & \multirow{2}{*}{$\begin{array}{c}\text { MED (kg) } \\
\text { H1 }\end{array}$} & \multicolumn{3}{|c|}{$\operatorname{PECD}\left(\mathrm{kg} \mathrm{ha}^{-1}\right)$} & \multirow{2}{*}{$\begin{array}{r}\mathrm{CE}(\mathrm{m}) \\
\mathrm{H} 1\end{array}$} & \multirow[b]{2}{*}{$\mathrm{H} 2$} \\
\hline & & & $\mathrm{H} 2$ & $\mathrm{H} 1$ & $\mathrm{H} 2$ & & \\
\hline \multirow{2}{*}{40.000} & 2009 & $0,179 \mathrm{a}$ & $0,186 a$ & $4.240 \mathrm{a}$ & $5.300 \mathrm{a}$ & $0,189 \mathrm{a}$ & $0,177 b$ \\
\hline & 2010 & $0,255 \mathrm{a}$ & $0,243 \mathrm{a}$ & $4.660 \mathrm{~b}$ & $6.800 \mathrm{a}$ & $0,181 \mathrm{a}$ & $0,172 \mathrm{a}$ \\
\hline \multirow{2}{*}{55.000} & 2009 & $0,185 b$ & $0,217 \mathrm{a}$ & $6.120 \mathrm{a}$ & $6.460 \mathrm{a}$ & $0,189 a$ & $0,183 a$ \\
\hline & 2010 & $0,229 \mathrm{a}$ & $0,232 \mathrm{a}$ & $4.500 \mathrm{~b}$ & $6.140 \mathrm{a}$ & $0,180 \mathrm{a}$ & $0,173 a$ \\
\hline \multirow{2}{*}{70.000} & 2009 & $0,199 \mathrm{a}$ & $0,191 \mathrm{a}$ & $5.920 \mathrm{~b}$ & $7.000 \mathrm{a}$ & $0,185 \mathrm{a}$ & $0,180 \mathrm{a}$ \\
\hline & 2010 & $0,238 \mathrm{a}$ & $0,231 \mathrm{a}$ & $5.800 \mathrm{a}$ & $7.180 \mathrm{a}$ & $0,180 \mathrm{a}$ & $0,168 b$ \\
\hline \multirow{2}{*}{85.000} & 2009 & $0,205 a$ & $0,205 a$ & $6.100 \mathrm{a}$ & $6.840 \mathrm{a}$ & $0,187 \mathrm{a}$ & $0,178 \mathrm{a}$ \\
\hline & 2010 & $0,217 \mathrm{a}$ & $0,217 \mathrm{a}$ & $6.100 \mathrm{a}$ & $6.600 \mathrm{a}$ & $0,178 \mathrm{a}$ & $0,172 \mathrm{a}$ \\
\hline \multirow{2}{*}{100.000} & 2009 & $0,174 b$ & $0,209 a$ & $6.160 \mathrm{~b}$ & $7.920 \mathrm{a}$ & $0,178 \mathrm{a}$ & $0,176 \mathrm{a}$ \\
\hline & 2010 & $0,219 \mathrm{a}$ & $0,226 \mathrm{a}$ & $8.440 \mathrm{a}$ & $8.960 \mathrm{a}$ & $0,172 \mathrm{a}$ & $0,168 \mathrm{a}$ \\
\hline
\end{tabular}

Médias seguidas por letras distintas na linha diferem entre si $(\mathrm{p}<0,05)$, pelo teste $\mathrm{F}$.

Fonte: Elaboração dos autores. 
Com relação ao comprimento de espigas, as médias de Tropical Plus foram superiores às de RB6324 (40.000 plantas ha ${ }^{-1}$ dentro de 2009; 70.000 plantas $h^{-1}$ dentro de 2010) (Tabela 3). Por sua vez, para diâmetro de espigas, resultados contrários foram obtidos (70.000 plantas ha ${ }^{-1}$ dentro de 2009; 70.000 plantas ha ${ }^{-1}$ dentro de 2010; 85.000 plantas ha $^{-1}$ dentro de 2010). Em termos de composição química, enquanto o conteúdo de açúcares totais nos grãos de Tropical Plus foi maior do que em RB6324 (70.000 plantas ha ${ }^{-1}$ dentro de 2009; 40.000 plantas ha-1 dentro de 2010; 55.000 plantas ha $^{-1}$ dentro de 2010), não foi observado resposta comum para o conteúdo de amido que possibilitasse afirmar superioridade de um híbrido em relação ao outro (Tabela 4).

Tabela 4. Desdobramento do efeito dos híbridos Tropical Plus (H1) e RB-6324 (H2) em função da população de plantas $(\mathrm{P})$ e do ano (A), referente às características diâmetro médio de espigas (DE), conteúdo médio de açúcares totais (AT) e de amido (AM).

\begin{tabular}{cccccccc}
\hline \multirow{2}{*}{$\begin{array}{c}\mathrm{P} \\
\text { (plantas ha-1 }\end{array}$} & A & \multicolumn{6}{c}{ Características } \\
\cline { 3 - 8 } & & DE (m) & H1 & H2 & H1 & H2 & AM (\%) \\
\hline \multirow{2}{*}{40.000} & 2009 & $0,0455 \mathrm{a}$ & $0,0466 \mathrm{a}$ & $26,69 \mathrm{a}$ & $27,10 \mathrm{a}$ & $16,00 \mathrm{~b}$ & $17,79 \mathrm{a}$ \\
& 2010 & $0,0466 \mathrm{a}$ & $0,0483 \mathrm{a}$ & $25,14 \mathrm{a}$ & $22,61 \mathrm{~b}$ & $15,69 \mathrm{~b}$ & $18,94 \mathrm{a}$ \\
\hline \multirow{2}{*}{55.000} & 2009 & $0,0437 \mathrm{a}$ & $0,0445 \mathrm{a}$ & $26,29 \mathrm{a}$ & $25,39 \mathrm{a}$ & $16,77 \mathrm{a}$ & $17,53 \mathrm{a}$ \\
& 2010 & $0,0463 \mathrm{a}$ & $0,0466 \mathrm{a}$ & $28,36 \mathrm{a}$ & $24,87 \mathrm{~b}$ & $15,23 \mathrm{~b}$ & $17,30 \mathrm{a}$ \\
\hline \multirow{2}{*}{70.000} & 2009 & $0,0427 \mathrm{~b}$ & $0,0453 \mathrm{a}$ & $27,31 \mathrm{a}$ & $25,45 \mathrm{~b}$ & $15,58 \mathrm{a}$ & $16,41 \mathrm{a}$ \\
& 2010 & $0,0463 \mathrm{~b}$ & $0,0484 \mathrm{a}$ & $29,78 \mathrm{a}$ & $29,20 \mathrm{a}$ & $16,16 \mathrm{a}$ & $16,91 \mathrm{a}$ \\
\hline \multirow{2}{*}{85.000} & 2009 & $0,0428 \mathrm{a}$ & $0,0445 \mathrm{a}$ & $25,72 \mathrm{a}$ & $26,16 \mathrm{a}$ & $16,69 \mathrm{a}$ & $15,33 \mathrm{~b}$ \\
& 2010 & $0,0464 \mathrm{~b}$ & $0,0485 \mathrm{a}$ & $29,93 \mathrm{a}$ & $29,98 \mathrm{a}$ & $14,91 \mathrm{~b}$ & $16,26 \mathrm{a}$ \\
\hline \multirow{2}{*}{100.000} & 2009 & $0,0422 \mathrm{a}$ & $0,0439 \mathrm{a}$ & $25,79 \mathrm{a}$ & $25,46 \mathrm{a}$ & $15,78 \mathrm{a}$ & $14,69 \mathrm{~b}$ \\
& 2010 & $0,0470 \mathrm{a}$ & $0,0482 \mathrm{a}$ & $30,43 \mathrm{a}$ & $30,28 \mathrm{a}$ & $14,97 \mathrm{a}$ & $15,55 \mathrm{a}$ \\
\hline
\end{tabular}

Médias seguidas por letras distintas na linha diferem entre si $(\mathrm{p}<0,05)$, pelo teste $\mathrm{F}$.

Fonte: Elaboração dos autores.

\section{Conclusões}

O incremento na população de plantas de 40.000 até 100.000 plantas ha $^{-1}$ resulta em maiores produtividades de espigas despalhadas dos híbridos Tropical Plus e RB-6324;

$\mathrm{O}$ aumento na população de plantas reduz o comprimento e o diâmetro de espigas dos híbridos Tropical Plus e RB-6324, e a massa de espigas do Tropical Plus, mas não afeta o padrão comercial e de uso industrial desses componentes de produção;

Em populações de plantas mais elevadas o híbrido RB-6324 produz espigas com grãos mais adocicados e com menores conteúdos de amido;

O híbrido Tropical Plus apresenta maiores massa, comprimento, produtividade, conteúdo de açúcares totais, e menor diâmetro de espigas do que o RB-6324.

\section{Referências}

ALBUQUeRQUE, C. J. B.; PINHO, R. G. V.; BORGES, I. D.; SOUZA FILHO, A. X.; FIORINI, I. V. A. Desempenho de híbridos experimentais e comerciais de milho para produção de milho verde. Ciência $e$ Agrotecnologia, Lavras, v. 32, n. 3, p. 768-775, 2008.

ANDREI, E. Compêndio de defensivos agrícolas. 7. ed. São Paulo: Organização Andrei Editora Ltda., 2005. $1133 \mathrm{p}$.

ARGENTA, G.; SILVA, P. R. F.; SANGOI, L. Arranjo de plantas em milho: análise do estado-da-arte. Ciência Rural, Santa Maria, v. 31, n. 6, p.1075-1084, 2001. 
BANZATTO, D. A.; KRONKA, S. N. Experimentação agrícola. 4. ed. Jaboticabal: FUNEP, 2006. 237 p.

BARBIERI, V. H. B.; LUZ, J. M. Q.; BRITO, C. H.; DUARTE, J. M.; GOMES, L. S.; SANTANA, D. G. Produtividade e rendimento industrial de híbridos de milho doce em função de espaçamento e populações de plantas. Horticultura Brasileira, Brasília, v. 23, n. 3, p. 826-830, 2005.

BRACHTVOGEL, E. L.; PEREIRA, F. R. S.; CRUZ, S. C. S.; BICUDO, S. J. Densidades populacionais de milho em arranjos espaciais convencional e equidistante entre plantas. Ciência Rural, Santa Maria, v. 39, n. 8, p. 23342339, 2009.

CANIATO, F. F.; GALVÃO, J. C. C.; FINGER, F. L.; PUIATTI, M.; OLIVEIRA, D. A.; FERREIRA, J. L. Quantificação de açúcares solúveis totais, açúcares redutores e amido nos grãos verdes de cultivares de milho na colheita. Ciência e Agrotecnologia, Lavras, v. 31, n. 6 p. 1893-1896, 2007.

CANIATO, F. F.; GALVÃO, J. C. C.; FINGER, F. L.; RIBEIRO, R. A.; MIRANDA, G. V.; PUIATTI, M. Composição de açúcares solúveis totais, açúcares redutores e amido nos grãos verdes de cultivares de milho na colheita. Revista Brasileira de Milho e Sorgo, Sete Lagoas, v. 3, n. 1, p. 38-44, 2004.

CARAMORI, P.; WREGE, M. S.; GONÇALVES, S. L.; GERAGE, A. C.; GOMES, J. Zoneamento agroclimático da cultura do milho no Estado do Paraná. Londrina: IAPAR, 1999. 24 p. (Informe de Pesquisa, 129).

CREECH, R. G. Genetic control of carbohydrate synthesis in maize endosperm. Genetics, Maryland, v. 52, n. 4, p. 1175-1185, 1965

Carbohydrate synthesis in maize. In: NORMAN, A. G. (Ed.). Advances in agronomy. New York: Academic, 1968. p. 275-289.

CRUZ, C. D.; REGAZZI, A. J. Modelos biométricos aplicados ao melhoramento genético. Viçosa: UFV, $2001.390 \mathrm{p}$.

CRUZ, J. C.; PEREIRA FILHO, I. A. Manejo e tratos culturais. In: PEREIRA FILHO, I. A. (Ed.). O cultivo do milho-verde. Brasília, DF: Embrapa Informação Tecnológica, 2003. p. 31-44.

EMPRESA BRASILEIRA DE PESQUISA AGROPECUÁRIA - EMBRAPA. Sistema de classificação de solos. Brasília: Embrapa Produção de Informações; Rio de Janeiro: Embrapa Solos, 2006. 306 p.

Centro Nacional de Pesquisa de Milho e Sorgo,

Sistema de produção de milho. 7. ed. Versão eletrônica.
Sete Lagoas: EMBRAPA- CNPMS, set. 2011. Disponível em: $<$ http://sistemasdeproducao.cnptia.embrapa.br/ FontesHTML/Milho/CultivodoMilho_7ed/index.htm>. Acesso em: 10 set. 2012.

FOOD AND AGRICULTURE ORGANIZATION OF UNITED NATIONS - FAO. FAOSTAT. Disponível em: $<$ http://faostat.fao.org/site/567/DesktopDefault. aspx?PageID=567\#ancor $>$. Acesso em: 6 mar. 2013.

FERREIRA, D. F. Manual do sistema Sisvar para análises estatísticas. Lavras: UFLA, 2000. 63 p. Disponível em: $<$ http://www.dex.ufla.br/ danielff/sisvarmanual.pdf $>$. Acesso em: 16 jun. 2010.

FLESCH, R. D.; VIEIRA, L. C. Espaçamento e densidade de milho com diferentes ciclos no Oeste de Santa Catarina, Brasil. Ciência Rural, Santa Maria, v. 34, n. 1, p. 25-31, 2004.

HILL, D. E. Yellow and bicolor supersweet corn trials 1999-2001. New Haven: The Connecticut Agricultural Experiment Station, 2002. 15 p. (Bulletin, 982).

INSTITUTO ADOLFO LUTZ - IAL. Métodos fisicoquímicos para análise de alimentos. Brasília: Ministério da Saúde, Agência Nacional de Vigilância Sanitária, 2005. 1018 p.

KVITSCHAL, M. V.; MANTINE, E.; VIDIGAL FILHO, P. S.; VIDIGAL, M. C. G.; SCAPIM, C. A. Arranjo de plantas e produção de dois híbridos simples de milho. Ciência Agronômica, Fortaleza, v. 41, n. 1, p. 122-131, 2010.

KWIATKOWSKI, A. Qualidade e composição química de híbridos simples de milho doce. 2007. Dissertação (Mestrado em Agronomia) - Universidade Estadual de Maringá, Maringá.

LAUGHNAN, J. R. The effect of the sh2 factor on carbohydrate reserves in the mature endosperm of maize. Genetics, Madison, v. 38, p. 485-489, 1953.

MAGGIO, M. A. Acúmulo de massa seca e extração de nutrientes por plantas de milho doce hibrido "Tropical". 2006. Dissertação (Mestrado em Agricultura Tropical e Subtropical) - Instituto Agronômico, Campinas.

MARTIN, T. N.; VENTURINI, T.; API, I.; PAGNONCELLI, A.; VIEIRA JÚNIOR, P. A. Perfil do manejo da cultura de milho no sudoeste do Paraná. Revista Ceres, Viçosa, v. 58, n. 1, p. 1-8, 2011.

OLIVEIRA JÚNIOR, L. F. G; SMITH, R. E. B.; REIS, F. O.; CAMPOSTRINI, O.; PEREIRA, M. G. Diferenças fisiológicas entre genótipos de milho doce (su-1) e milho comum durante o desenvolvimento. Scientia Agraria, Curitiba, v. 8, n. 4, p. 351-356, 2007. 
PAIVA JÚNIOR, M. C.; VON PINHO, R. G.; VON PINHO, E. V. R.; RESENDE, S. G. de. Desempenho de cultivares para a produção de milho verde em diferentes épocas e densidades de semeadura em Lavras - MG. Ciência e Agrotecnologia, Lavras, v. 25, n. 5, p.12351247, 2001.

PARENTONI, S. N.; GAMA, E. E. G.; MAGNAVACA, R.; REIFSCHSNEIDER, F. J. B.; VILLAS BOAS, G. L. Milho doce. Informe Agropecuário, Belo Horizonte, v. 14, n. 165, p. 17-22, 1990.

PEREIRA FILHO, I. A.; CRUZ, J. C.; GAMA, E. E. G. Cultivares para o consumo verde. In: PEREIRA FILHO, I. A. (Ed.). O cultivo do milho verde. Brasília: Embrapa, 2003. p. 17-30.

PEREIRA FILHO, I. A.; CRUZ, J. C. Cultivares de milho para o consumo verde. Sete Lagoas: Embrapa/CNPMS, 2002. 7 p. (Circular técnica, 15).

PIANA, A. T.; SILVA, P. R. F.; BREDEMEIER, C.; SANGOI, L.; VIEIRA, V. M.; SERPA, M. S.; JANDREY, D. B. Densidade de plantas de milho híbrido em semeadura precoce no Rio Grande do Sul. Ciência Rural, Santa Maria, v. 38, n. 9, p. 2608-2612, 2008.

RAIJ, B. van; CANTARELLA, H.; QUAGGIO, J. A.; FURLANI, A. M. C. (Ed.). Recomendações de adubação e calagem para o Estado de São Paulo. 2. ed. Campinas: IAC, 1996. 285 p. (Boletim técnico, 100).

RITCHIE, S. W.; HANWAY, J. J.; BENSON, G. O. How a corn plant develops. Ames: Iowa State University of Science and Technology. Cooperative Extension Service, 1993. (Special Report, n. 48).

ROCHA, D. R. Desempenho de cultivares de milho verde submetidas a diferentes populações de plantas em condições de irrigação. 2008. Tese (Doutorado em Agronomia) - Universidade Estadual Paulista, Jaboticabal.

SANGOI, L. Understanding plant density effects on maize growth and development: an important issue to maximize grain yield. Ciência Rural, Santa Maria, v. 31, n. 1, p. 159-168, 2001.

SANGOI, L.; ENDER, M.; GUIDOLIN, A. F.; ALMEIDA, M. L.; HEBERLE, P. C. Influence of row spacing reduction on maize grain yield in regions with a short summer. Pesquisa Agropecuária Brasileira, Brasília, v. 36, n. 6, p. 861-869, 2001.

SANGOI, L.; ALMEIDA, M. L.; GRACIETTI, M. A.; HORN, D.; SCHWEITZER, C.; SCHIMITT, A.; BIANCHET, P. Rendimento de grãos, produção e distribuição de massa seca de híbridos de milho em função do aumento da densidade de plantas. Revista Brasileira de Agrociência, Pelotas, v. 11, n. 1, p. 25-31, 2005.

SANGOI, L.; ALMEIDA, M. L.; SILVA, P. R. F.; ARGENTA, G. Bases morfo-fisiológicas para a maior tolerância dos híbridos modernos de milho a altas densidades de plantas. Bragantia, Campinas, v. 61, n. 2, p. 101-110, 2002.

SILVA, P. R. F.; PIANA, A. T.; MAASS, L. B.; SERPA, M. S.; SANGOI, L.; VIEIRA, V. M.; ENDRIGO, P. C.; JANDREY, D. B. Adequação da densidade de plantas à época de semeadura em milho irrigado. Revista de Ciências Agroveterinárias, Lages, v. 9, n. 1, p. 48-57, 2010.

SILVA, P. S. L.; DUARTE, S. R.; OLIVEIRA, F. H. T. Efeito da densidade de plantio sobre o rendimento de espigas verdes de cultivares de milho desenvolvidas em diferentes épocas. Horticultura Brasileira, Brasília, v. 25, n. 2, p. 154-158, 2007.

STRIEDER, M. L.; SILVA, P. R. F.; ARGENTA, G.; RAMBO, L.; SANGOI, L.; SILVA, A. A.; ENDRIGO, P. C. A resposta do milho irrigado ao espaçamento entre linhas depende do híbrido e da densidade de plantas. Ciência Rural, Santa Maria, v. 37, n. 3, p. 634-642, 2007.

TAIZ, L.; ZEIGER, E. Fotossíntese: reações de carboxilação. In: _. Fisiologia vegetal. Porto Alegre: Artmed, 2004. p. 173-198.

UNITED STATES DEPARTMENT OF AGRICULTURE - USDA. U.S. Sweet corn statistics. 2010. Disponível

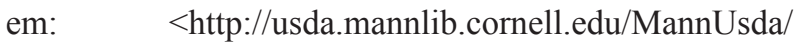
viewDocumentnfo.do?documentI $\mathrm{D}=1564>$. Acesso em: 15 ago. 2010.

VALENTINUZ, O. R.; TOLLENAAR, M. Vertical profile of leaf senescence during the grain filling period in older and newer maize hybrids. Crop Science, Madison, v. 44, n. 3, p. 827-834, 2004.

WILLIAMS, M. M. Agronomics and economics of plant population density on processing sweet corn. Field Crops Research, v. 128, n. 1, p. 55-61, 2012.

WOLF, E. A. Possibilities of improving eating quality of shipped fresh corn with high sugar retention property of the shrunken-2 character. Proceedings of the Florida State Horticultural Society, Florida, v. 75, p. 236-239, 1962.

ZÁRATE, N. A. H.; VIEIRA, M. C.; SOUSA, T. M.; RAMOS, D. D. Produção e renda líquida de milho verde em função da época de amontoa. Semina: Ciências Agrárias, Londrina, v. 30, n. 1, p. 95-100, 2009. 
